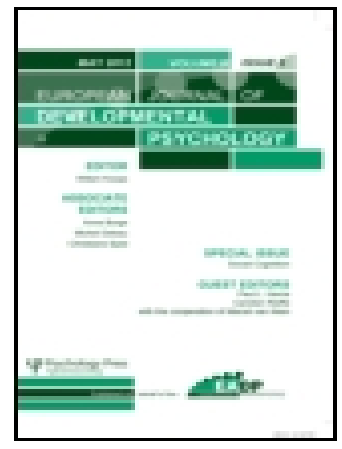

European Journal of Developmental Psychology

\title{
Rage and revenge: Highly aggressive boys' explanations for their responses to ambiguous provocation
}

\section{Bram Orobio de Castro, Esmée E. Verhulp \& Kevin Runions}

To cite this article: Bram Orobio de Castro, Esmée E. Verhulp \& Kevin Runions (2012) Rage and revenge: Highly aggressive boys' explanations for their responses to ambiguous provocation, European Journal of Developmental Psychology, 9:3, 331-350, DOI: 10.1080/17405629.2012.680304

To link to this article: https://doi.org/10.1080/17405629.2012.680304

\section{Published online: 08 May 2012.}

\section{Submit your article to this journal $\llbracket$}

Llll Article views: 409

Q View related articles $\longleftarrow$

Citing articles: 20 View citing articles $[7$ 


\title{
Rage and revenge: Highly aggressive boys' explanations for their responses to ambiguous provocation
}

\author{
Bram Orobio de Castro ${ }^{1}$, Esmée E. Verhulp ${ }^{1}$, and Kevin Runions ${ }^{2}$ \\ ${ }^{1}$ Department of Developmental Psychology, Utrecht University, Utrecht, The \\ Netherlands \\ ${ }^{2}$ Department of Educational Psychology and Leadership Studies, University of \\ Victoria, Victoria, BC, Canada
}

\begin{abstract}
Children adapt their behaviour to their social environment through adequate social information processing (SIP). According to the SIP model, social information processing is goal oriented. Yet the subjective experience of reactively and severely aggressive children seems to be that their behaviour is impelled by uncontrollable rage, with no other goal in mind than venting anger and spite. To test whether reactive and proactive aggression by severely aggressive boys were related with experiences of goal directedness, 52 highly aggressive and 30 normal comparison boys were asked to explain their responses to hypothetical provocations by peers. Both highly aggressive and normal comparison boys primarily explained generation and selection of aggressive responses to provocation situations by feeling impelled to act by strong emotions, not with reference to outcome goals. Reactive aggression was specifically related with such emotion explanations for aggression. Moreover, highly aggressive boys more frequently advocated aggression by referring to emotions and referring to a moral rule that taking revenge is imperative, regardless of its consequences. Highly aggressive boys expected their responses to have more negative relational outcomes than comparison boys.
\end{abstract}

Keywords: Aggressive behaviour; Social cognition; Social information processing.

Anyone who has ever experienced a fit of rage can testify to the subjective experience: Rage seems to take control over one's behaviour and to impel

Correspondence should be addressed to Bram Orobio de Castro, Department of Developmental Psychology, Utrecht University, PO Box 80.140, NL-3508 TC, Utrecht, The Netherlands. E-mail: b.castro@fss.uu.nl

(C) 2012 Psychology Press, an imprint of the Taylor \& Francis Group, an Informa business http://www.psypress.com/edp http://dx.doi.org/10.1080/17405629.2012.680304 
one to behave aggressively. If any thoughts come to mind, they seem limited to focusing one's attention on more cues to fuel anger. In this state, there seems to be no time or motivation to consider the detrimental consequences of one's aggressive behaviour, even though one would clearly foresee these consequences in a less agitated state.

It may very well be that some aggressive behaviour in children is also primarily driven by such strong emotional impulses, given the negative consequences aggressive behaviour tends to have for perpetrators (e.g., Ladd, 2006) and the impulsive nature of many aggressive acts (Berkowitz, 2008). This may be particularly true for reactively aggressive behaviour. Reactive aggression is aggressive behaviour performed in anger, in reaction to a presumed threat, whereas proactive aggression is planned, instrumental and "cold blooded" behaviour (Dodge, 1991). Research indicates that these forms of aggression are related to different precursors, correlates, and prognoses (Vitaro, Brendgen, \& Barker, 2006; Vitaro, Brendgen, \& Tremblay, 2002).

Yet the subjective experience of uncontrolled rage as a source of reactively aggressive behaviour does not seem to fit well with the influential social information processing model (SIP; Crick \& Dodge, 1994; Lemerise \& Arsenio, 2000) of aggressive responses to social stimuli. According to the SIP model, aggressive children respond aggressively to social situations becausecompared to non-aggressive peers - they encode different information, represent this information differently, pursue fewer social goals, generate more aggressive responses, and from these select a more aggressive response for enactment. Numerous studies have shown that children with aggressive behaviour problems do indeed process social information atypically (e.g., de Castro, Veerman, Koops, Bosch, \& Monshouwer, 2002; Dodge, 2006; Horsley, de Castro, \& Van der Schoot, 2010; Lansford et al., 2006).

Goal directedness has a pivotal role in social information processing theory. In theory, children generate a number of possible responses to a social situation, and from these, select the response they expect will help them to attain their goals. Children with behaviour problems may then generate and select more aggressive responses because they pursue atypical goals and because they expect to attain these goals by means of aggressive behaviour (Crick \& Dodge, 1994; Lochman, Wayland, \& White, 1993).

This pivotal role of goals, however, seems to be at odds with the subjective experience of rage. Could it be that severely aggressive behaviour does, on many occasions, not follow from the conscious pursuit of goals? Both research (e.g., Hubbard et al., 2004) and clinical observation suggest that severely aggressive behaviour is often a very emotional, impulsive response to a perceived provocation. Emotion theories (e.g., Frijda, 1993; Levenson, 1999) suggest that such highly emotional reactions to salient signals of threat or harm may be triggered directly by rudimentary, automatic primary appraisal processes, that leave little time or resources for 
in-depth processing of the effects that possible (aggressive) responses might have on outcome goals. Rather than the process of setting interaction goals and evaluating possible responses against them, a direct emotional process seems to be triggered, directly linking global cues of threat or harm to a dominant, prepotent, aggressive response (De Castro, 2004; Levenson, 1999).

Given the important role of goals in the SIP model, surprisingly little research concerning goals in SIP has been conducted. The importance of atypical goals for aggressive behaviour is supported in part by studies concerning children's (Erdley \& Asher, 1996) and adolescent boys' (Lochman et al., 1993) explanations for their responses to hypothetical social events. In such studies behaviour problems were found to be associated with goals of dominance (i.e., instrumental goals), that may best be attained by aggressive responses, whereas non-aggressive behaviour was associated with affiliative goals (i.e., relational goals), that may best be attained by nonaggressive responses. In addition, proactively aggressive children have been found to select more instrumental than relational goals when given the choice (Salmivalli \& Peets, 2009; Salmivalli, Ojanen, Haanpa, \& Peets, 2005). Even though these studies provide important information on relations between goal preference and aggressive behaviour, they do not provide evidence that aggressive behaviour does actually result from the conscious pursuit of goals.

According to the dual-processing model of SIP (De Castro, 2004), children may not necessarily consciously pursue any goal, or "try to do" anything when they act aggressively. In emotionally challenging provocative situations, children may engage in pre-emptive processing of salient emotional cues, which may impel them to attribute hostile intent to whomever "provoked" them, to become angry, and to execute a dominant aggressive response before they have carefully represented a situation, set goals, generated multiple responses, and selected one of them. Findings on aggressive boys' emotions (Arsenio, Adams, \& Gold, 2009; De Castro, Merk, Koops, Veerman, \& Bosch, 2005; Lemerise \& Arsenio, 2000) suggest that they may feel driven towards aggressive behaviour by hostile intent attribution (De Castro et al., 2002), instilling intense anger (De Castro et al., 2005; Hubbard et al., 2004) taking "control precedence" (e.g., Frijda, 1993). This anger at the perceived hostile "provocation", in the absence of effective inhibitory control, may directly recruit aggressive responses (Runions \& Keating, 2010). In their own experience, anger and rage make them behave aggressively even when they realize that the behaviour will not help them attain their goals, and even though they would never select these aggressive responses in a less emotional state. Thus, some children may respond aggressively to social provocations because they feel driven to do so by their intense emotions that they cannot regulate, not because they generate and select an aggressive response that they expect to help them attain their goals. 
To be precise, we propose that such impulsive aggressive behaviour is not deliberately goal oriented. We do not exclude the possibility that such impulsive aggression is sub- or unconsciously motivated by underlying goals or concerns that evoke strong emotional action tendencies to behave aggressively (e.g., Frijda, 1993). We do propose that the behaviour is not experienced as goal directed.

\section{The present study}

To our knowledge no study has ever directly tested whether aggressive behaviour by highly aggressive children derives from the deliberate pursuit of goals or not. In the studies described above, goal directedness is an assumption that is used to construct measures, but this assumption is not directly tested itself. By posing question such as, "What would you be trying to do?" (Erdley \& Asher, 1996), participants are prompted to describe their behaviour in terms of goals that they were presumably pursuing. The very real possibility that participants were not pursuing a goal or trying to do anything in particular is not taken into account. Similarly, in studies with closed-response formats, participants were asked to indicate the importance of, or preference for, specific predefined goals (Crick \& Ladd, 1990; Lemerise, Fredstrom, Kelley, Bowersox, \& Waford, 2006; Salmivalli et al., 2005). Again, indicating that no goals were pursued was no option.

To examine the hypothesis that aggressive behaviour is not necessarily deliberately goal oriented, we assumed that this absence of goal orientation would be evident in children's responses to structured questions asked when presented with various scenarios depicting ambiguous provocation situations. Previous research assumed that children always pursue goals and consequently used measures that presuppose instrumental and/or relational goals. To date, the possibility that children do not (experience that they) pursue goals at all with their aggressive behaviour, but are driven to aggressive acts by their strong emotions, has not been tested. The current study aimed to do so by allowing children to explain their behaviour not only in terms of goals, but also in terms of emotions. In line with the above, it was hypothesized that aggressive responses to provocation would be generally explained by reference to emotions, not to goals.

Reactively and proactively aggressive behaviours result from specific deviations in SIP (Arsenio et al., 2009; Dodge, Lochman, Harnish, Bates, \& Pettit, 1997). With regard to social goals, it has been suggested that reactive and proactive aggression may be uniquely related to different goals for aggressive behaviour in social interactions (Dodge, 1991). Proactive aggression has been found to be related to instrumental and dominance goals (Arsenio et al., 2009; Salmivalli et al., 2005) in general population samples. However, the picture is less clear for reactive aggression and for 
aggressive behaviour by children with severe aggressive behaviour problems. In theory, both reactive aggression and severe forms of aggression displayed by children with behaviour disorders seem more likely to result from preemptive emotional processing of social stimuli, and less likely to be deliberately goal oriented, because both reactive aggression and aggressive behaviours by children with disruptive behaviour disorders are associated with heightened emotionality and poorer inhibition (De Castro, 2004).

Thus, we also aimed to test whether goal directedness differed between boys with aggressive behaviour problems and less aggressive peers, and between reactive and proactive functions of aggression. Highly aggressive boys were hypothesized to use fewer goal-related explanations, and were expected instead to generate more emotion-driven explanations for their responses than were their non-aggressive counterparts. Second, reactive aggression was expected to be specifically related to a lack of specific goals and reference to strong emotions to explain aggressive behaviours. By definition, proactive aggression was expected to be uniquely associated with conscious goal-driven motivations, as demonstrated by more positive evaluations of expected instrumental outcomes.

To test these hypotheses, we presented ambiguous provocation vignettes to boys in special care for aggressive behaviour problems and to normal comparison boys and asked them to generate and select responses. Then, we asked them to explain why they generated and selected these responses, and which outcomes they expected to follow their responses. Unlike prior research, we did not prime or direct them to reflect on their social goals, but instead encouraged more open-ended accounts of their experiences. In addition, participants were asked to judge several aggressive responses to the vignettes and explain why they (dis)approved of them.

\section{METHOD}

\section{Participants}

Eighty-two 7- to 13-year-old boys participated as part of a larger study (see De Castro et al., 2005). Participants in the highly aggressive group $(n=54)$ were recruited from behaviour disorders departments of clinics for child psychiatry $(n=24)$ and special education for children with behaviour problems $(n=30)$ in the Netherlands. In the Netherlands, children are only referred to these two types of institutions if the severity of their behaviour problems significantly impairs social functioning and prohibits participation in regular education, according to parents, teachers, and diagnosticians. All boys between 7 and 13 years of age with a disruptive behaviour disorder in the participating facilities were invited to participate, except for boys with a pervasive developmental disorder or manifest psychosis. All invited boys in 
this group chose to participate. All but two clinic-referred participants were diagnosed with DSM-IV (American Psychiatric Association, 1994) oppositional defiant disorder by clinic psychiatrists, in five cases comorbid with attention deficit hyperactivity disorder (ADHD), in two cases with conduct disorder, and in one case with reactive attachment disorder. No diagnoses were obtained for the remaining two boys because these were not given at their treatment facility. Clinic- and special-education referred boys did not differ in mean aggressive or delinquent behaviour problems. Therefore, type of referral was not included in further analyses. The non-referred comparison group $(n=30)$ was recruited from two elementary schools in low to middle socioeconomic status neighbourhoods of the same cities. In these schools, five boys per classroom were randomly selected and asked to participate in the study. All but two boys agreed to participate.

Groups differed significantly on teacher-rated externalizing behaviour problems. As expected, these problems were more severe in the aggressive $(M=65.0, S D=9.4)$ than in the comparison group $(M=54.6, S D=5.3), F(1$, $82)=37.8, p<.001$. In the aggressive group, $93 \%$ of participants received Teacher Report Form (TRF) aggressive behaviour scores in the borderline or clinical range. Aggressive boys were also considered more reactively $(M=3.45, S D=0.88)$ and proactively aggressive $(M=2.55, S D=1.02)$ than comparison boys $(M=2.38, S D=0.91$ and $M=1.56, S D=0.56)$, respective $F \mathrm{~s}(1,82)=28.1,24.1, p \mathrm{~s}<.001$. Age did not differ between groups.

\section{Procedure}

Participants were individually tested in a quiet room in the clinic or at their school. Participants were first shown the cassette recorders used to play vignettes and to record their answers. In a standardized instruction they were told they were going to listen to stories of events that could happen to them, and would be asked what they would do if the events actually happened to them. Participants were asked to imagine they experienced the stories themselves. It was emphasized that no wrong answers could be given, and participants were assured of the confidentiality of their answers.

Eight audio taped vignettes (based on De Castro et al., 2005) were presented. All vignettes concerned being hindered by a peer whose intentions were ambiguous. As part of a larger study on SIP and emotion, participants answered a number of questions about each vignette. After hearing a vignette, participants were asked how they would respond to the presented situation, why they would respond in that way, and what would happen if they responded that way. Next, participants were presented two responses to the vignette that had supposedly been given previously by other boys. One of these responses was clearly aggressive, but functional for obtaining a desired instrumental outcome. The other response was a 
non-aggressive attempt to solve the social problem. These responses were presented in randomized order. After each presented response participants were asked whether they would enact a similar response themselves, whether they (dis)approved of the response and to explain why they (dis)approved.

\section{Measures}

\section{Aggression and behaviour problems}

Aggression and other behaviour problems were assessed with the TRF and the Reactive and Proactive Aggression Questionnaire. The Dutch version (Verhulst, van der Ende, \& Koot, 1997) of the TRF (Achenbach, 1991) contains 118 multiple-choice behaviour items and two open-ended questions. For each multiple-choice item, teachers indicate 0 (Not true for the child), 1 (Somewhat true for the child), or 2 (Very often true for the child). Achenbach (1991) reported high 15-day test-retest reliability, two-month stability, and validity for this instrument. Norms for Dutch children (Verhulst et al., 1997) were used to calculate $T$-scores for behaviour problems. The 6-item Reactive and Proactive Aggression Questionnaire (Hendrickx, Crombez, Roeyers, \& De Castro, 2003) is a Dutch translation of the reactive and proactive aggression items in the Teacher Rating of Aggression (TRA) developed by Dodge and Coie (1987). Three items describe reactive aggression, for example: "When this child has been teased or threatened, he or she gets angry easily and strikes back". The other three items describe proactive aggression, for example: "This child uses physical force in order to dominate other kids". The answer format is a 5-point Likert scale ranging from 1 (Never) to 5 (Almost always). Reliability, factor structure, and validity are adequate for both the original (e.g., Hubbard et al., 2004) and the Dutch version (Hendrickx et al., 2003). Cronbach's alphas in this sample were .87 for reactive aggression and .90 for proactive aggression. Reactive and proactive aggression were highly correlated, $r=.71, p<.001$, as is typically found with this measure (Polman, De Castro, Koops, van Boxtel, \& Merk, 2007).

\section{Social cognition}

Three constructs were studied: (1) boys' explanations for their responses to vignettes, referred to hereafter as response explanations; (2) their outcome expectancies for their own responses; and (3) boys' explanations for their (dis)approval of the hypothetical aggressive responses we presented to them, referred to hereafter as selection explanations. These constructs were operationalized as follows. 
Response explanations. After describing how they would respond to a vignette, participants were asked why they would respond in the way they had described. Their answers to the latter question were coded following the decision tree depicted in Figure 1. Each answer was coded for containing arguments: "In favour of aggression"; "Against aggression"; "In favour of solution"; and/or "Against solution". Within each of these four categories two kinds of arguments were distinguished: "emotions" (e.g., "Because I'm so angry") and "goals". Goals were in turn coded as "moral" (e.g., "Then we're even"), or "outcome" goals. Within the outcomes goals, a further

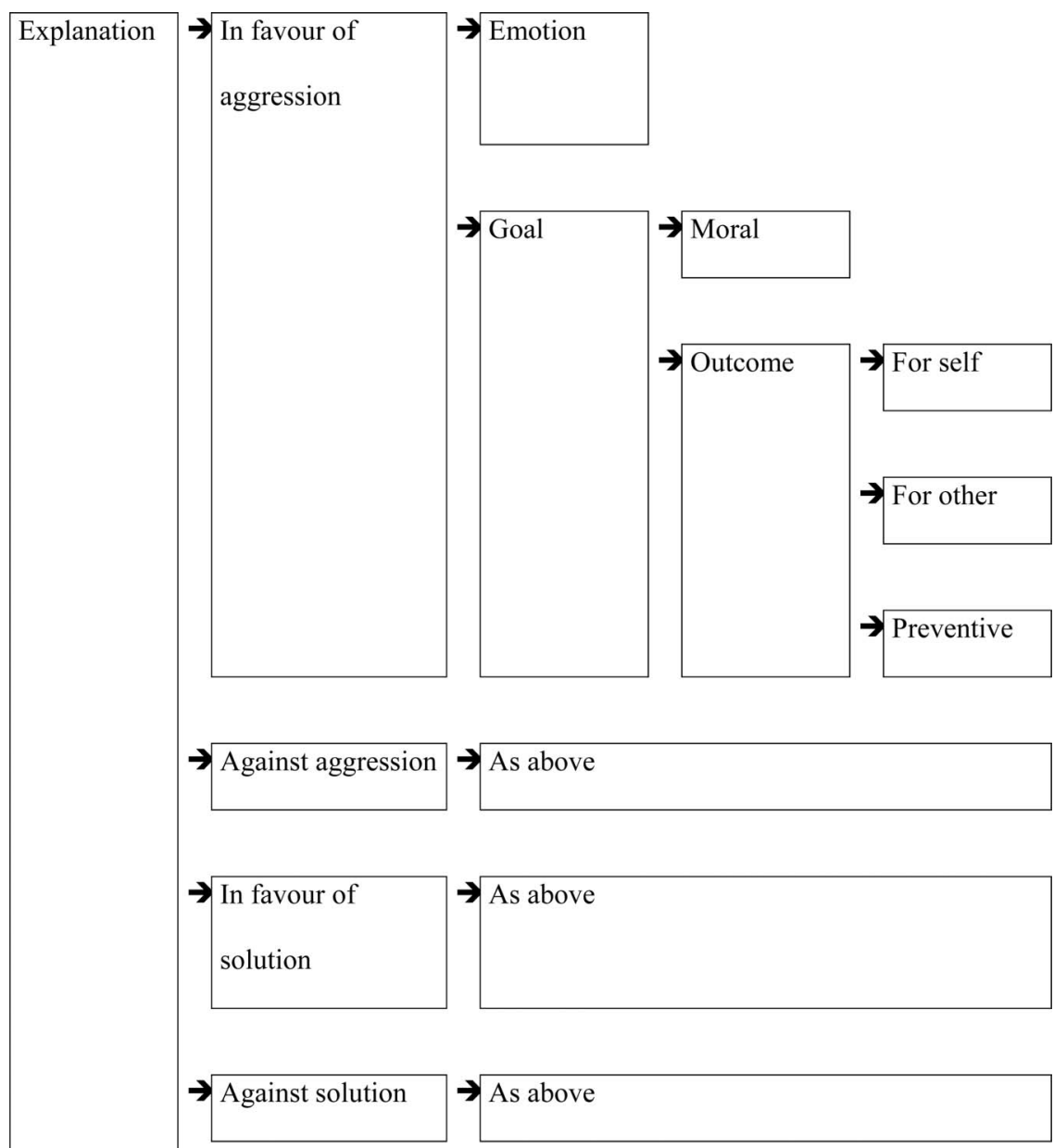

Figure 1. Decision tree. 
distinction was made between "outcomes for self" (e.g., "So I can play again"), "outcomes for other" (e.g., "So his painting will be ruined"), and "prevention" (e.g., "It will keep him from doing it again"). All responses were coded by two independent raters. Mean inter-rater agreement for response explanation codes was $89 \%$, and mean kappa was .60 .

Note that the above categories are not mutually exclusive, as a single answer may contain both arguments in favour of aggression and against solutions (or the opposite), and may contain several types of arguments. For example, the statement: "You shouldn't fight, and if I ask him to help we'll both have a painting" contains a moral argument against aggression, as well as an argument in favour of a solution with outcome goals for self and other.

For each participant, we initially counted how many times each argument type was used. As there were eight vignettes, this resulted in scores for each type of argument with a minimum of 0 (Never used the argument) and a maximum of 8 (Used the argument with every vignette).

Outcome expectancies. After describing how and why they would respond to a vignette, participants were asked what they expected to happen after their response. Their answers to this question were divided into four groups, specifically: (i) positive relational outcomes; (ii) negative relational outcomes; (iii) positive instrumental outcomes; and (iv) negative instrumental outcomes. Relational outcomes concerned any aspect of the relation between the participant and the provocateur (e.g., "We'll fight", or "We'll play together"). Instrumental outcomes concerned any nonrelational loss or gain for the participant (e.g., "I'll get to play again", I'll be hungry"). The average inter-rater agreement for these codes was $86 \%$, mean kappa was .76.

The number of vignettes for which each outcome was mentioned was then counted. This resulted in variables for positive relational, negative relational, positive instrumental, and negative instrumental expected outcomes, with minimum values ranging from 0 (Never mentioned this outcome) to 8 (Mentioned this outcome for each vignette).

Selection explanations. After being asked to judge aggressive responses to the vignettes we presented, participants were asked to explain why they (dis)approved of the presented responses. Answers to these questions were again coded by means of the decision tree in Figure 1. Each answer was coded for containing arguments: "In favour of aggression"; and/or "Against aggression". In each of the two categories "In favour of aggression" and "Against aggression, we distinguished "emotion" and "goals", as in the previous section. Goals were again subdivided into "moral" goals and "outcomes". Again, these categories were not mutually exclusive, as a single answer could contain several types of arguments. For example, the statement: 
"I'll get punished, but it's fair to smudge his painting 'cause he did that too" contains both a moral argument in favour of aggression and a negative outcome for the self as an argument against aggression. As for response explanations, the number of times each argument type was used was counted, resulting in variables with a minimum score of 0 (Never used the argument type) and a maximum score of 8 (Used the argument type with all vignettes).

\section{Data analyses}

As explained above, response explanation variables were created by summing the number of times a specific answer was given. Variables resulting from this summation were strongly skewed, reflecting that some boys used different types of arguments for different vignettes (resulting in low scores for each distinct argument type), while other boys used the same type of argument for all vignettes (resulting in high scores for that type of argument). To enable hypothesis testing despite the skewness of these variables, all response explanation variables were reduced to dichotomous variables with the values "Never used this argument" and "Used this argument at least once". Further data analyses are based on these dichotomous variables.

To test the hypothesis that aggressive children use fewer goal-related and more emotion explanations for aggressive responses than their peers, we first examined whether aggressive responses were explained with reference to goals to begin with. Next, the associations between group status (aggressive/ non-aggressive) and providing specific explanations were tested with chisquare analyses for each type of explanation.

We conducted regression analysis for the whole sample to test whether reactive aggression was specifically related with a lack of specific goals but rather with reference to strong emotions to explain aggressive behaviours, whereas proactive aggression was uniquely associated with more positive evaluations of expected instrumental outcomes. Reactive and proactive aggression were strongly correlated, $r=.71$. Therefore, in these analyse, one type of aggression (e.g., reactive aggression) served as the focal outcome variable. The other type of aggression (e.g., proactive aggression) was controlled for by entering it as first predictor variable in the regression equation. The relevant dichotomous response explanation variables were then added as dummy variables.

\section{RESULTS}

\section{Response explanation}

The percentage of participants in each group that mentioned each kind of argument is shown in Table 1. Arguments in favour of aggression were 
TABLE 1

Explanations for own responses to ambiguous provocation by highly aggressive and comparison boys

\begin{tabular}{|c|c|c|c|c|}
\hline \multirow[b]{2}{*}{ Explanation } & \multicolumn{2}{|c|}{ Highly aggressive } & \multicolumn{2}{|c|}{$N C$} \\
\hline & $\%$ of group & $\%$ of group & $p$ & $\varphi$ \\
\hline In favour of aggression & 94 & 72 & .009 & .31 \\
\hline Emotion & 81 & 52 & .007 & .31 \\
\hline \multicolumn{5}{|l|}{ Goals: } \\
\hline - Moral & 75 & 52 & .030 & .24 \\
\hline - Outcome & 46 & 31 & $n s$ & \\
\hline - For self & 29 & 21 & $n s$ & \\
\hline - Preventive & 23 & 3 & .018 & .26 \\
\hline - For other & 17 & 7 & $n s$ & \\
\hline Against aggression & 19 & 52 & .003 & .34 \\
\hline Emotion & 2 & 14 & $n s$ & \\
\hline \multicolumn{5}{|l|}{ Goals: } \\
\hline - Moral & 8 & 28 & .020 & .27 \\
\hline - Outcome & 17 & 48 & .004 & .33 \\
\hline - For self & 14 & 31 & $n s$ & \\
\hline - Preventive & 2 & 10 & $n s$ & \\
\hline - For other & 10 & 31 & .018 & .27 \\
\hline In favour of solution & 88 & 90 & $n s$ & \\
\hline Emotion & 40 & 43 & & \\
\hline \multicolumn{5}{|l|}{ Goals: } \\
\hline - Moral & 58 & 57 & & \\
\hline - Outcome & 65 & 70 & & \\
\hline - For self & 52 & 53 & & \\
\hline - Preventive & 23 & 23 & & \\
\hline - For other & 20 & 27 & & \\
\hline Against solution & 4 & 3 & $n s$ & \\
\hline Emotion & 0 & 0 & & \\
\hline \multicolumn{5}{|l|}{ Goals: } \\
\hline - Moral & 2 & 3 & & \\
\hline - Outcome & 2 & 0 & & \\
\hline - For self & 2 & 0 & & \\
\hline - Preventive & 0 & 0 & & \\
\hline - For other & 0 & 0 & & \\
\hline
\end{tabular}

Note: Numbers denote the percentage of participants in a group using the particular explanation at least once. Categories are not mutually exclusive, therefore percentages do not add up to $100 \%$. Highly aggressive $=$ Highly aggressive group, $\mathrm{NC}=$ normal comparison group. $p=$ one-tailed $p$ for group $(\mathrm{NC} /$ Highly aggressive $) \times$ explanation (mentioned/not mentioned) chi-square $(1,81)$ test. $n s=$ not significant.

mentioned by relatively more highly aggressive than normal comparison boys, $\chi^{2}(1)=7.55, p$ (one-sided $)=.009, \varphi=.31$. The most frequent types of arguments in favour of aggression were emotional and moral, and the types 
of arguments in favour of aggression also differed between groups. As hypothesized, emotion was given as an explanation for aggression by more highly aggressive than comparison boys ( $81 \%$ vs. $52 \%$, respectively), $\chi^{2}(1)=7.53, p$ (one-sided) $=.007, \varphi=.31$. Moral arguments in favour of aggression were also given by relatively more highly aggressive than comparison boys $\left(75 \%\right.$ vs. $52 \%$, respectively), $\chi^{2}(1)=4.54, p$ (one-side$\mathrm{d})=.030, \varphi=.24$. Highly aggressive boys mentioned prevention of future conflicts as a reason for aggression more often than did the comparison boys $(23 \%$ vs. $3 \%$, respectively $), \chi^{2}(1)=5.32, p($ one-sided $\left.)=.018, \varphi=.26\right)$. Thus, in line with our hypotheses, aggressive behaviour was predominantly explained by emotions, rather than by pursuing specific outcomes.

We were interested to observe that not all emotion explanations in favour of aggression concerned negative affect. An explorative distinction between negative and positive affect in the emotion explanations for aggression revealed that all arguments in favour of aggression given by comparison boys concerned negative affect, whereas seven highly aggressive boys (13\%) mentioned positive affect as a reason to behave aggressively (e.g., "Because I like to do it", "It's fun").

Arguments against aggression were given more often by comparison than by highly aggressive boys, $\chi^{2}(1)=9.21, p$ (one-sided) $=.003, \varphi=.34$. Outcomes and norms were the most frequently mentioned arguments against aggression and were used by relatively more normal comparison than highly aggressive boys (respectively), $\chi^{2}(1)=8.78, p($ one-sided $)=.004, \varphi=.33$ and $\chi^{2}(1)=5.84, p($ one-sided $\left.)=.020, \varphi=.27\right)$.

Groups did not differ with respect to frequency or type of arguments in favour of solution attempts. The argument types that were most frequently presented in favour of solutions were outcomes and moral arguments.

Arguments against solution attempts were extremely rare across groups. Of all 656 explanation answers ( 82 participants $\times 8$ vignettes), only seven $(1.07 \%)$ contained an argument against attempted solutions. This finding is consistent with our hypothesis that aggressive behaviour does not result from atypical goal pursuit. If the aggressive boys had preferred aggression over solutions, they would have given reasons not to prefer solutions, but such reasons were clearly hardly ever given.

\section{Specific relations with reactive and proactive aggression}

Our regression analyses indicated that, after controlling for proactive aggression, reactive aggression was uniquely predicted by emotion explanations $(\beta=0.20, p=.011$. Proactive aggression was not uniquely predicted by any response explanation variable, after controlling for its 
covariance with reactive aggression. This provides support for our hypothesis that emotion, and not conscious social goals, are implicated in reactive aggression.

\section{Outcome expectancies}

Status group differences in outcome expectancies were tested by means of a two Group (highly aggressive/normal comparison) multivariate analysis of variance (MANOVA) with positive relational, negative relational, positive instrumental, and negative instrumental outcome expectancies as dependent variables and Quality (positive/negative) and Outcome Type (relational/ instrumental) as within-subject factors.

A main effect of Quality was observed; both groups mentioned more positive than negative expected outcomes, $F(1,79)=17.56, p=.000$, $\eta_{\mathrm{p}}{ }^{2}=.18$. This effect was qualified by a Quality-by-Group interaction, $F(1$, $79)=9.05, \quad p=.004, \quad \eta_{\mathrm{p}}{ }^{2}=.10$, indicating that highly aggressive boys mentioned relatively more negative expected outcomes than comparison boys did. According to Cohen's criteria (1988), these effects are both of large size. The interaction, however, was in turn qualified by a three-way interaction with Outcome Type, $F(1,79)=7.36, p=.008, \eta_{\mathrm{p}}{ }^{2}=.08$. Means depicted in Figure 2 and Table 2 show that the more frequent mention of negative outcomes by the highly aggressive group was specifically due to more frequent mention of negative relational outcomes. This effect was of medium size (Cohen, 1988).

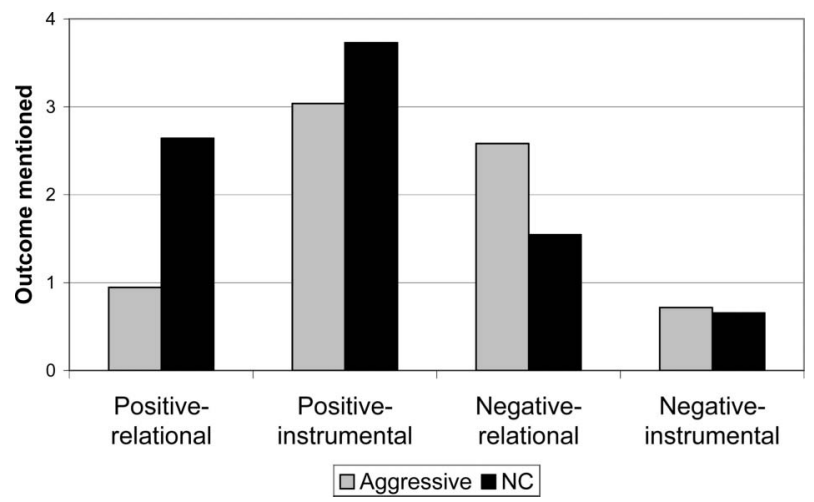

Figure 2. Outcome expectancies for own responses to ambiguous provocation by highly aggressive and comparison boys. Note: Bars indicate the mean number of vignettes for which each outcome expectancy was mentioned. Highly aggressive $=$ Highly aggressive group $(n=54)$, $\mathrm{NC}=$ normal comparison group $(n=27)$. 


\section{Selection explanation}

Next, we analysed the explanations that participants gave for their relative preferences for the presented aggressive and solution-attempt responses. The percentage of participants in each group that mentioned each argument type is shown in Table 3. Arguments in favour of aggressive response selection were mentioned more often by highly aggressive than by comparison boys $(M=2.00, S D=1.94$ and $M=0.97, S D=1.59$, respectively), $t(1,81)=2.49$, $p=.008$, whereas arguments against aggression were mentioned less often by

TABLE 2

Outcome expectancies for own responses to ambiguous provocation by highly aggressive and comparison boys

\begin{tabular}{lcc}
\hline & Highly aggressive & $N C$ \\
\cline { 2 - 2 } Expected outcome & $M(S D)$ & $M(S D)$ \\
\hline Positive-relational & $0.94(1.46)$ & $2.64(2.31)$ \\
Positive-instrumental & $3.04(2.15)$ & $3.73(2.41)$ \\
Negative-relational & $2.58(2.15)$ & $1.54(2.01)$ \\
Negative-instrumental & $0.72(1.05)$ & $0.65(0.98)$ \\
\hline
\end{tabular}

TABLE 3

Explanations for the evaluation of aggressive responses by highly aggressive and comparison boys

\begin{tabular}{|c|c|c|c|}
\hline \multirow[b]{2}{*}{ Explanation } & \multicolumn{2}{|c|}{ Highly aggressive } & \multirow{2}{*}{$\frac{N C}{p}$} \\
\hline & $\%$ of group & $\%$ of group & \\
\hline \multicolumn{4}{|c|}{ In favour of aggression } \\
\hline Emotion & 25 & 10 & $n s$ \\
\hline \multicolumn{4}{|l|}{ Goals: } \\
\hline - Moral & 62 & 27 & .001 \\
\hline - Outcome & 38 & 23 & $n s$ \\
\hline \multicolumn{4}{|c|}{ Against aggression } \\
\hline Emotion & 8 & 13 & $n s$ \\
\hline \multicolumn{4}{|l|}{ Goals: } \\
\hline - Moral & 87 & 73 & $n s$ \\
\hline - Outcome & 87 & 90 & $n s$ \\
\hline
\end{tabular}

Note: Numbers denote the percentage of participants in a group using the particular explanation at least once. Categories are not mutually exclusive, therefore percentages do not add up to $100 \%$. Highly aggressive $=$ referred group $(n=52), \mathrm{NC}=$ normal comparison group $(n=30) . p=$ one-tailed $p$ for group ( $\mathrm{NC} /$ Highly aggressive) $\times$ explanation (mentioned/not mentioned), chi-square $(1,81)$ test. $n s=$ not significant. 
highly aggressive than by comparison boys $(M=4.63, S D=2.42$ and $M=6.20, S D=2.07$, respectively), $t(1,81)=2.99, p=.002$.

In both groups, arguments in favour of aggressive response selection were most often moral. Relatively more highly aggressive than comparison boys used moral arguments in favour of aggression, $\chi^{2}(1)=9.71, p<.001$. Emotions and outcomes were used equally often by both groups as arguments in favour of aggression. Groups did not differ in the types of arguments against aggression they used.

Qualitative analyses of the arguments used in favour of, and against, aggression, suggest that highly aggressive boys' moral arguments in favour of aggression were frequently based on a moral rule that "getting even" is a justifiable and warranted response to the perceived injustice of being hindered or provoked. That is, even if aggressive behaviour is expected to lead to negative outcomes for both boys involved (e.g., not getting what they wanted or being punished by a teacher), this would be preferable to "dishonest" solutions where both boys would be better off, but not be "even". In contrast, comparison boys' arguments against aggression generally referred to honesty and the desirability of outcomes, where a beneficial solution for all involved is preferable to "getting even", even if this means the provocateur will be better of than the participant. Table 4 contains examples of both types of arguments.

\section{DISCUSSION}

It was hypothesized that highly aggressive boys' explanations for aggressive responses to ambiguously intended provocations would predominantly concern emotions, rather than goals. As expected, highly aggressive boys

\section{TABLE 4}

Examples of explanations used in the evaluation of aggressive responses by highly aggressive and comparison boys

\begin{tabular}{lr}
\hline In favour of aggression & Against aggression \\
\hline $\begin{array}{l}\text { I think that's normal ... then that boy's } \\
\text { lemonade is gone too ... } \\
\text { even. }\end{array}$ & $\begin{array}{r}\text { It's a bit stupid and it doesn't get you } \\
\text { anywhere. Your toy is not fixed by } \\
\text { breaking his toy. }\end{array}$ \\
$\begin{array}{l}\text { I'd just do it back. Then he'll get even angrier } \\
\text { and I think it's fair, then he has as much } \\
\text { bad luck as me. }\end{array}$ & $\begin{array}{r}\text { It doesn't help you much. He'll have nothing } \\
\text { and you'll have nothing either. }\end{array}$ \\
$\begin{array}{c}\text { Because (...) then I make him sad too. } \\
\text { I don't like him spoiling my fun, but if he's } \\
\text { having fun then I'm not someone who's } \\
\text { going to spoil his fun too. }\end{array}$ \\
\hline
\end{tabular}

Note: The presented explanations in favour of aggression were given by highly aggressive boys, while the explanations against aggression were given by comparison boys. 
used significantly more emotion explanations for aggressive responses than their non-aggressive counterparts and rarely referred to specific social goals. In fact, overall, both highly aggressive and normal comparison boys explained aggressive responses to provocation situations primarily by referring to their emotions. Expected outcomes were rarely used as explanations of aggressive responses, either among the highly aggressive boys or the normal control boys. When response explanations referred to goals, moral explanations were given most frequently, especially by the highly aggressive boys. As in previous studies (Erdley \& Asher, 1996; Lochman et al., 1993) revenge was frequently mentioned as a moral argument favouring aggressive responses. Highly aggressive boys also more frequently mentioned expected outcomes as explanation of aggressive responses when they expected that aggression would prevent future provocations.

Roughly half of the boys in the comparison group presented arguments against aggressive responses that were based on expected negative outcomes for themselves and the provocateur, and/or on moral disapproval of aggressive behaviour. In contrast, less than a quarter of the highly aggressive boys mentioned arguments against aggression. In both groups, nonaggressive responses to provocation were mostly explained by their expected positive outcomes. Arguments against solutions were rarely given.

Although more highly aggressive boys did put forward arguments in favour of aggression, they did not generally expect positive outcomes to follow aggressive behaviour. On the contrary, they expected more negative relational outcomes than did the comparison group. It appears that boys in the highly aggressive group do appreciate that aggressive behaviour will lead to negative relational outcomes, but this appreciation does not keep them from acting aggressively. Their aggressive acts, rather than being motivated by expected consequences, seem - in their own eyes - determined by anger, the obligation to take revenge, and - for a minority of aggressive boys - the positive feelings associated with being aggressive.

The proposition that aggressive behaviour is explained by referring to intense negative emotions was only partly supported. Emotions were indeed the most frequent explanations for reactively aggressive boys. However, some boys did not explain aggressive behaviour with negative, but with positive emotions, saying that they enjoy being aggressive. Their responses suggest that for them "revenge is sweet". From the perspective of "an eye for an eye", taking revenge may be "doing the right thing" and instil a sense of pride. This is in line with a recent finding in non-referred children of an association between proactive aggression and feeling happy after responding aggressively to provocation (Arsenio et al., 2009). Unfortunately, in the present study the number of positive emotion explanations for aggression was too small to assess specificity to proactive aggression.

Clearly, the notion that a response would be generated and selected because boys expect it to help attain a desired outcome is not supported by 
boys' own explanations for their responses. Highly aggressive boys give aggressive responses, even though they expect these to have negative relational consequences for themselves. Expected instrumental outcomes for aggression were generally lower than for non-aggressive responses. When goals were referred to, aggressive responses were not primarily explained in terms of outcomes boys try to attain, but in terms of a moral goal, particularly taking revenge, that was valued as a goal in itself.

Superficially, it may seem paradoxical that highly aggressive boys' explanations are more concerned with norms and values than comparison boys' responses. However, a closer look suggests that the highly aggressive boys refer to specific moral values that promote aggressive behaviour rather than discourage it. These values may be summarized as "there is an obligation to get even", "revenge prevents future conflicts", and "fear of aversive consequences is a weakness". These "moral" standpoints may be particularly important for highly aggressive boys, as they frequently come from coercive family backgrounds (Patterson, 1982) and participate in peer groups where these norms are advocated (Dishion, Spracklen, Andrews \& Patterson, 1996). "Getting even", coercion of others through aggressive behaviour, and defying threats of negative consequences can be considered functional adaptations to these family and peer systems, where forgiving, compromising, and fear of conflicts may only weaken one's position (Thompson \& Calkins, 1996).

In view of the finding for response explanation that seven boys said they enjoyed acting aggressively, it is noteworthy that our operationalization of "negative relational outcome" reflects outcomes that coders consider "negative", not the boys themselves. This most frequently involved getting into fights. Although these outcomes certainly seem negative for the relation between the participant and the provocateur, they need not necessarily be considered "negative" by the subgroup of aggressive participants who say they enjoy fighting in response to provocation.

The finding that there were no differences with regard to outcome expectancies between proactive and reactive functions of aggression contradicts previous findings (Salmivalli et al., 2005; Vitaro et al., 2006). An explanation for this finding might be that there was a high correlation between proactive and reactive aggression in this sample $(r=.71)$. In order to differentiate more clearly between these two forms of aggression, measures should be used that disentangle both form and function of proactive and reactive aggression (Polman et al., 2007). An alternative explanation for not finding differences in outcome expectancies for reactive and proactive aggression may be that all boys in the highly aggressive group were evidently referred to treatment for rather severe problems in their daily functioning. Possibly, this selection excluded proactively aggressive boys with more positive outcome expectancies for their own behaviour.

It should be noted that this study relied on self-generated response explanations. The self-reported explanations for behaviour presented in this 
study should certainly not be taken to represent the actual causes of these behaviours. People generally have very little insight into the actual causes of their behaviours, and there is no reason to expect this to be different for highly aggressive boys. Even if children report that their aggressive responses are caused by their emotions, this certainly does mean that the emotion has causal priority in the production of those behaviours. It is possible that an aggressive response is explained in moral terms, but was in fact given because the child in question could not think of a non-aggressive solution to the problem, or due to another, completely unrelated cause.

Moreover, it might be possible that children do have goals, and that their actions are based upon these, with the children having no conscious awareness of these goals. According to Austin and Vancouver (1996), latent goals may exist, that is, individuals may pursue goals even though they are not aware of this. However, as far as we know, there is no research concerning aggressive behaviour by children to support this idea to date, nor have social information processing researchers addressed this issue conceptually. We believe that future theoretical development could fruitfully address the potential role of conscious versus subconscious processing, and how latent or automatic processes diverge from consciously experienced processes in the production of social behaviours.

Nevertheless, and notwithstanding this potential discrepancy between consciously accessed, self-reported explanations, and actual causes of behaviour, children's own explanations for their aggressive behaviours are interesting phenomena in themselves. They may help us understand children's theories of social interaction and morality and may serve as a starting point for cognitive behavioural treatment. It is easier to (motivate clients to) discuss, challenge, or alter cognitions if one addresses what clients themselves see as causes for their problematic behaviour. Finally, as "experts" in their own right, children may propose hypotheses concerning causes of aggressive behaviour that adult researchers have not yet thought of. The positive feelings associated with taking revenge at the expense of one's own relations provide a clear example in case.

\section{REFERENCES}

Achenbach, Th. M. (1991). Manual for the Teacher's Report Form and 1991 profiles. Burlington, VT: University of Vermont, Department of Psychiatry.

American Psychiatric Association. (1994). Diagnostic and statistical manual of mental disorders (4th ed.; DSM-IV). Washington, DC: Author.

Arsenio, W. F., Adams, E., \& Gold, J. (2009). Social information processing, moral reasoning, and emotion attributions: Relations with adolescents' reactive and proactive aggression. Child Development, 80, 1739-1755.

Austin, J. T., \& Vancouver, J. B. (1996). Goal constructs in psychology: Structure, process, and content. Psychological Bulletin, 120, 338-375. 
Berkowitz, L. (2008). What I meant to say: Some thoughts in response to Pahlavan and Dodge. Aggressive Behavior, 34, 136-138.

Cohen, J. (1988). Statistical power analysis for the behavioral sciences. Hillsdale, NJ: Lawrence Erlbaum Associates, Inc.

Crick, N. C., \& Dodge, K. A. (1994). A review and reformulation of social informationprocessing mechanisms in children's social adjustment. Psychological Bulletin, 115, 74-101.

Crick, N. R., \& Ladd, G. W. (1990). Children's perceptions of the outcomes of social strategies: Do the ends justify being mean? Developmental Psychology, 26, 612-620.

De Castro, B. O. (2004). The development of social information processing and aggressive behavior: Current issues. European Journal of Developmental Psychology, 2, 87-102.

De Castro, B. O., Merk, W., Koops, W., Veerman, J. W., \& Bosch, J. D. (2005). Emotions in social information processing and their relations with reactive and proactive aggression in referred aggressive boys. Journal of Clinical Child and Adolescent Psychology, 34, 105-116.

De Castro, B. O., Veerman, J. W., Koops, W., Bosch, J. D., \& Monshouwer, H. J. (2002). Hostile attribution of intent and aggressive behavior: A meta-analysis. Child Development, 73, 916-934.

Dishion, T. J., Spracklen, K. M., Andrews, D. W., \& Patterson, G. R. (1996). Deviancy training in male adolescent friendships. Behavior Therapy, 27, 373-390.

Dodge, K. A. (1991). The structure and function of reactive and proactive aggression. In D. Pepler \& K. H. Rubin (Eds.), The development and treatment of childhood aggression (pp. 201-218). Hillsdale, NJ: Lawrence Erlbaum Associates, Inc.

Dodge, K. A. (2006). Translational science in action: Hostile attributional style and the development of aggressive behavior problems. Development and Psychopathology, 18, 791814.

Dodge, K. A., \& Coie, J. D. (1987). Social-information processing factors in reactive and proactive aggression in children's peer groups. Journal of Personality and Social Psychology, $53,1146-1158$.

Dodge, K. A., Lochman, J. E., Harnish, J. D., Bates, J. E., \& Pettit, G. S. (1997). Reactive and proactive aggression in school children and psychiatrically impaired chronically assaultive youth. Journal of Abnormal Psychology, 106, 37-51.

Erdley, C., \& Asher, S. (1996). Children's social goals and self-efficacy perceptions as influences on their responses to ambiguous provocation. Child Development, 67, 1329-1344.

Frijda, N. H. (1993). The place of appraisal in emotion. Cognition and Emotion, 7, 357-387.

Hendrickx, M., Crombez, G., Roeyers, H., \& De Castro, B. O. (2003). Psychometrische evaluatie van de Nederlandstalige versie van de Agressie Beoordelingsschaal van Dodge en Coie (1987) [Psychometric evaluation of the Dutch version of Doge \& Coie's (1987) aggression rating scale]. Tijdschrift voor Gedragstherapie, 36, 33-43.

Horsley, T. A., De Castro, B. O., \& Van der Schoot, M. (2010). In the eye of the beholder: Eyetracking assessment of social information processing in aggressive behavior. Journal of Abnormal Child Psychology, 38, 587-599.

Hubbard, J. A., Parker, E. H., Ramsden, S. R., Flanagan, K. D., Relyea, N., Dearing, K. F., et al. (2004). The relations among observational, physiological, and self-report measures of children's anger. Social Development, 13, 14-39.

Ladd, G. W. (2006). Peer rejection, aggressive or withdrawn behavior, and psychological maladjustment from ages 5 to 12: An examination of four predictive models. Child Development, 77, 822-846.

Lansford, J. E., Malone, P. S., Dodge, K. A., Crozier, J. C., Pettit, G. S., \& Bates, J. E. (2006). A $12-$ year prospective study of patterns of social information processing problems and externalizing behaviors RID F-6851-2011. Journal of Abnormal Child Psychology, 34, 715-724.

Lemerise, E. A., \& Arsenio, W. F. (2000). An integrated model of emotion processes and cognition in social information processing. Child Development, 71, 107-118. 
Lemerise, E. A., Fredstrom, B. K., Kelley, B. M., Bowersox, A. L., \& Waford, R. N. (2006). Do provocateurs' emotions displays influence children's social goals and problem solving? Journal of Abnormal Child Psychology, 34, 559-571.

Levenson, R. W. (1999). The intrapersonal functions of emotion. Cognition and Emotion, 13, 481-504.

Lochman, J., Wayland, K., \& White, K. (1993). Social goals: Relationship to adolescent adjustment and to social problem solving. Journal of Abnormal Child Psychology, 21, 135151.

Patterson, G. R. (1982). Coercive family processes. Eugene, OR: Castalia.

Polman, H., De Castro, B. O., Koops, W., van Boxtel, H. W., \& Merk, W. W. (2007). A metaanalysis of the distinction between reactive and proactive aggression in children and adolescents. Journal of Abnormal Child Psychology, 35, 522-535.

Runions, K. C., \& Keating, D. P. (2010). Anger and inhibitory control as moderators of children's hostile attributions and aggression. Journal of Applied Developmental Psychology, 31, 370-378.

Salmivalli, C., Ojanen, T., Haanpa, J., \& Peets, K. (2005). "I'm OK but you're not” and other peer-relational schemas: Explaining individual differences in children's social goals. Developmental Psychology, 41, 363-375.

Salmivalli, C., \& Peets, K. (2009). Pre-adolescents' peer-relational schemas and social goals across relational contexts. Social Development, 18, 817-832.

Thompson, R. A., \& Calkins, S. D. (1996). The double-edged sword: Emotional regulation for children at risk. Development and Psychopathology, 8, 163-182.

Verhulst, F. C., van der Ende, J., \& Koot, H. M. (1997). Handleiding voor de Teacher's Report Form (TRF): Nederlandse Versie [Manual for the TRF: Dutch version]. Rotterdam, the Netherlands: Afdeling Kinder- en jeugdpsychiatrie, Sophia Kinderziekenhuis/Academisch Ziekenhuis Rotterdam/Erasmus Universiteit Rotterdam.

Vitaro, F., Brendgen, M., \& Barker, E. D. (2006). Subtypes of aggressive behaviors: A developmental perspective. International Journal of Behavioral Development, 30, 12-19.

Vitaro, F., Brendgen, M., \& Tremblay, R. E. (2002). Reactively and proactively aggressive children: Antecedent and subsequent characteristics. Journal of Child Psychology and Psychiatry, 43, 495-505. 